\title{
PRODUKSI RUMPUT BENGGALA (Panicum maximum cv. Jacq) YANG DIBERIKAN PUPUK BIO-SLURRY BABI
}

\author{
Albertus V.B. Ladiwa, Malcky M. Telleng, Jeanette M. E. Soputan*, C. I. J. Sumolang \\ Fakultas Peternakan Universitas Sam Ratulangi Manado, 95115
}

\begin{abstract}
ABSTRAK
Penelitian ini bertujuan untuk mengetahui pengaruh pemberian pupuk bio-slurry terhadap produksi rumput benggala (Panicum maximum $\mathrm{cv}$. Jacq). Penelitian dilaksanakan selama 3 bulan di rumah kaca Fakultas Peternakan Universitas Sam Ratulangi, Manado, Sulawesi Utara. Rancangan percobaan yang digunakan dalam penelitian ini adalah Rancangan Acak Lengkap (RAL) dengan 4 perlakuan yaitu: tanpa pupuk (B0), 10 ton/ha (B1), 20 ton/ha (B2), dan 30 ton/ha (B3) dan masing-masing perlakuan diulang sebanyak 4 kali sehingga terdapat 16 satuan percobaan. Variabel yang diamati yaitu produksi berat segar daun, produksi berat segar batang, produksi berat kering daun, produksi berat kering batang. Hasil analisis keragaman menunjukkan bahwa pemberian pupuk bio-slurry berpengaruh sangat nyata $(\mathrm{P}<0,01)$ terhadap berat segar daun, berat segar batang, berat kering daun dan berat kering batang. Hasil uji lanjut BNJ menunjukan bahwa perlakuan 30 ton/ha menghasilkan berat segar daun, berat segar batang, berat kering daun dan berat kering batang yang berbeda sangat nyata $(\mathrm{P}<0,01)$ lebih tinggi dari tanpa pupuk, 10 ton/ha, dan 20 ton/ha (B2). Disimpulkan bahwa pemberian pupuk bio-slurry level 30 ton/ha memberikan produksi berat segar
\end{abstract}

*korespondensi (corresponding author) Email: jeanettesoputan@ymail.com daun, berat segar batang, berat kering daun dan berat kering batang rumput benggala yang paling tinggi.

Kata kunci: produksi, rumput benggala, bio-slurry

\section{ABSTRACT}

THE PRODUCTION OF BENGAL GRASS (Panicum maximum cv. Jacq) GIVEN BIO-SLURRY FERTILIZER OF PIG. This research aimed the role of bio-slurry fertilizer on the production of Bengal grass (Panicum Maximum $\mathrm{Cv}$. Jacq). The study was conducted for 3 months in the greenhouse of the Sam Ratulangi University Manado Faculty of Animal Husbandry. North Sulawesi. The experimental design used in this study was a completely randomized design (CRD) with four treatments, that: without fertilizer (B0), 10 tons / ha (B1), 20 tons / ha (B2), and 30 tons / ha (B3). Each treatment replicated 4 times and gave 16 experimental units. The variables were the production of fresh weight of leaves, the production of fresh stem weight, the production of leaf dry weight, production stem dry weight. The results of this study concluded that 30 tons/ha (B3) bio-slurry had highest fresh weight of leaves, fresh weight of stems and the dry weight of leaves, and dry weight of stems.

Keywords: production, bengal grass, bioslurry 


\section{PENDAHULUAN}

Di Indonesia ternak ruminansia memiliki peranan yang sangat penting dalam memenuhi kebutuhan daging nasional. Kebutuhan daging nasional sebagian besar merupakan kontribusi dari peternakan rakyat. Permasalahan yang dihadapi peternak saat ini adalah rendahnya produktivitas ternak sebagai dampak dari rendahnya kualitas dan kuantitas hijauan pakan. Hijauan pakan merupakan bagian yang terpenting dalam peternakan ruminansia, lebih dari $70 \%$ ransum ternak terdiri atas pakan hijauan. Seiring dengan bertambahnya populasi penduduk, maka ketersediaan lahan yang dapat digunakan untuk pengembangan hijauan makanan ternak semakin berkurang, karena telah digunakan untuk pengembangan pertanian pangan, infrastruktur dan permukiman.

\section{Rumput benggala (Panicum}

maximum $c v$. Jacq) merupakan salah satu tanaman pakan ternak yang memiliki potensi dan kandungan nutrien yang cukup baik. Fanindi dan Sutedi (2014) menyatakan rumput benggala (Panicum maximum cv. Gatton) mempunyai nilai nutrisi BK: 8,80\%, PK: 5,98\%, LK: 2,24\%, SK: 36,38\%, Abu: 9,98\%, Ca: 1,09\%, P: 0,41\% dan Energi: 4034. Produksi tanaman rumput benggala (Panicum maximum $\mathrm{cv}$. Jacq) sangat dipengaruhi oleh faktor tumbuh tanaman meliputi air, sinar matahari maupun unsur hara baik yang berasal dari tanah maupun dari udara $(\mathrm{C}, \mathrm{H}$, O) (Purbajanti et al, 2010).

Produktifitas hijauan pakan dipengaruhi oleh nutrien dalam tanah, hal ini terkait dengan pupuk dan jarak tanam. Setiap tanaman mempunyai tingkat pemupukan yang berbeda. Salah satu pupuk organik yang dapat digunakan adalah pupuk bio-slurry. Kandungan nurtisi bioslurry, bahan organik $65,88 \%$, C-Org $15,60 \%$, N-Tot 1,57, C/N 9,97, $\mathrm{P}_{2} 0_{5} 1,92 \%$, $\mathrm{K}_{2} \mathrm{O}$ 0,41 (Agus S. 2013). Penelitian ini bertujuan untuk mengetahui pengaruh tingkat pemberian pupuk bio-slurry terhadap produksi rumput benggala (Panicum maximum cv. Jacq) mengunakan 4 level pemberian pupuk bio-slurry.

\section{MATERI DAN METODE PENELITIAN}

Penelitian dilaksanakan di rumah kaca, Fakultas Peternakan Universitas Sam Ratulangi Manado selama 3 bulan. Rumput yang digunakan adalah rumput benggala (P.maximum cv. Jacq) yang diambil dari desa Sea. Tanah yang digunakan diambil dari desa Warembungan dan bio-slurry diambil dari desa Sumarayar. Alat yang di gunakan cangkul, ayakan, pengukur, gunting, polybag, timbangan.

Penelitian menggunakan Rancangan Acak Lengkap (RAL), 4 
perlakuan dengan masing-masing perlakuan diulang sebanyak 4 kali sehingga terdapat 16 satuan percobaan. Model rancangan percobaan adalah:

$\mathrm{Y}_{\mathrm{ij}}=\mu+\tau_{\mathrm{i}+} \Sigma_{\mathrm{ij}}$

Keterangan :

$\mathrm{Y}_{\mathrm{ij}}=$ Variabel yang akan dianalisis pada ulangan ke-I perlakuan ke-j

$\mu=$ Rata-rata secara sebenarnya (nilai tengah populasi)

$\tau_{\mathrm{i}}=$ Pengaruh perlakuan ke-i

$\Sigma_{\mathrm{ij}}=$ Galat percobaan pada perlakuan keI ulangan ke-j

Perlakuan terdiri dari 4 dosis pupuk bio slurry yaitu:

$\mathrm{B} 0=$ tanpa pemberian pupuk

$\mathrm{B} 1=10$ ton/ha (25 gram pupuk/ polybag)

B2 $=20$ ton/ha (50 gram pupuk/ polybag)

B3 = 30 ton/ha (75 gram pupuk/ polybag)

Apabila terdapat perbedaan yang nyata $(\mathrm{P}<0,05)$ antara perlakuan maka akan dilanjutkan dengan uji Beda Nyata Jujur (BNJ).

\section{Variabel Penelitian}

Variabel yang diamati pada penelitian ini meliputi: Produksi berat segar daun, produksi berat segar batang, produksi berat kering daun dan produksi berat kering batang.

\section{Prosedur Penelitian}

1. Pengolahan Tanah. Tanah diayak mengunakan ayakan kawat dengan ukuran lubang $2 \mathrm{~mm} \times 2 \mathrm{~mm}$.

2. Pemupukan. Pemupukan di bagi 4 level pupuk B0, B1, B2 dan B3 yang langsung di homogenkan dengan tanah.

3. Penanaman Bibit. Tiap polybag ditanami satu rumput dan disediakan cadangan di polybag yang lain untuk mencegah tidak tumbunya bibit yang di tanam.

4. Pemeliharaan Tanaman. Penyiraman di lakukan pagi dan sore, pemberantasan hama dan gulma seminggu sekali.

5. Pemotongan. Rumput ditrimming pada umur 4 minggu, selanjutnya 8 minggu sesudah trimming rumput dipotong 5 $\mathrm{cm}$ di atas permukaan tanah.

6. Penimbangan. Setelah rumput di potong, rumput ditimbang untuk mendapatkan berat segar dan berat kering

7. Pengeringan. Daun dan batang dijemur salama 5 hari, setelah itu di masukan ke oven selama 2 hari pada suhu $60^{\circ} \mathrm{C}$ untuk mendapatkan berat kering.

\section{HASIL DAN PEMBAHASAN}

\section{Produksi Berat Segar Daun}

Pengaruh perlakuan level pupuk bio-slurry terhadap produksi berat segar daun rumput benggala (Panicum maximum 
cv. Jacq) dapat dilihat pada Tabel 1 . Produksi berat segar daun berkisar 10,31 sampai 20,00 gram/tanaman. Hasil penelitian ini lebih tinggi dibandingkan dengan penelitian Fernandes et al. (2014) yang menyatakan berat segar daun 16,58 gram/tanaman. Dari perbandingan di atas menunjukan penelitian ini memiliki hasil penelitian yang lebih baik.

Hasil analisis keragaman menunjukkan bahwa perlakuan pemberian level pupuk bio-slurry memberikan pengaruh yang berbeda sangat nyata $(\mathrm{P}<0,01)$ terhadap produksi berat segar daun. Uji BNJ menunjukkan level pupuk bio-slurry 30 ton/ha memberikan produksi berat segar daun yang sangat nyata $(\mathrm{P}<0,01)$.

Pemberian pupuk bio-slurry dengan level pupuk 30 ton/ha (B3) memberikan hasil produksi berat segar daun yang lebih tinggi sesuai dengan pernyataan Witariadi dan Candraasih (2018) jenis bio-slurry ternak babi memberikan hasil yang baik terhadap produksi rumput benggala (Panicum maximum cv. Trichoglume) dengan dosis bio-slurry 30 ton/ha.

Produksi tanaman rumput benggala (Panicum maximum $c v$. Jacq) sangat dipengaruhi oleh faktor tumbuh tanaman meliputi air, sinar matahari maupun unsur hara baik yang berasal dari tanah maupun dari udara (C, H, O) (Purbajanti et al., 2010). Namun hal ini berbanding terbalik dengan pernyataan Arnawa et al. (2014) bahwa penggunaan bio-slurry dengan dosis 10-30 ton/ha memberikan pengaruh yang sama terhadap produksi rumput benggala (Panicum maximum cv. Trichoglume). Pemberian pupuk organik merangsang pertumbuhan mikroorganisme tanah yang berperan membantu mengikat unsur hara baik dari tanah maupun udara dan

Tabel 1. Produksi Berat Segar Daun (gram/tanaman).

\begin{tabular}{ccccc}
\hline \multirow{2}{*}{ Ulangan } & \multicolumn{4}{c}{ Bio-slurry } \\
\cline { 2 - 5 } & $\begin{array}{c}\text { B0 } \\
\text { kontrol }\end{array}$ & $\begin{array}{c}\text { B1 } \\
(25 \text { gram })\end{array}$ & $\begin{array}{c}\text { B2 } \\
(50 \text { gram })\end{array}$ & $\begin{array}{c}\text { B3 } \\
(75 \text { gram })\end{array}$ \\
\hline 1 & 09,75 & 11,75 & 16,00 & 18,50 \\
2 & 09,75 & 11,50 & 17,25 & 19,75 \\
3 & 10,00 & 13,25 & 18,75 & 20,50 \\
4 & 11,75 & 12,25 & 21,00 & 21,25 \\
\hline Rataan & $10,31 \pm 0,97^{\mathrm{b}}$ & $12,19 \pm 0,77^{\mathrm{b}}$ & $18,25 \pm 2,15^{\mathrm{a}}$ & $20,00 \pm 2,56^{\mathrm{a}}$ \\
\hline \multicolumn{2}{r}{ Keterangan } & Rataan pada kolom yang sama dengan superskrip yang berbeda dalam huruf besar berarti berbeda \\
& sangat nyata $(\mathrm{P}<0,01)$. Rataan pada kolom yang sama dengan superskrip ns berarti berbeda tidak
\end{tabular}


membantu menggemburkan tanah (Sutedjo dan Kartasapoetra, 2005).

\section{Produksi Berat Segar Batang}

Pengaruh perlakuan level pupuk bio-slurry terhadap produksi berat segar batang rumput benggala (Panicum maximum $c v$. Jacq) dapat dilihat pada Tabel 2. Produksi berat segar batang berkisar 20,97 sampai 44,06 gram/tanaman. Hasil penelitian ini lebih tinggi dibadingkan dengan penelitian Fernandes et al. (2014) produksi berat segar batang 13,56 gram. Dari perbandingan di atas menunjukan penelitian ini memiliki hasil penelitian yang lebih baik.

Hasil analisis keragaman menunjukkan bahwa perlakuan pemberian level pupuk bio-slurry memberikan pengaruh yang berbeda sangat nyata $(\mathrm{P}<0,01)$ terhadap produksi berat segar batang. Uji BNJ menunjukkan level pupuk bio-slurry 30 ton/ha memberikan produksi berat segar batang yang sangat nyata $(\mathrm{P}<0,01)$.

Pemberian pupuk bio-slurry dengan level pupuk 30 ton/ha (B3) memberikan hasil produksi berat segar batang yang lebih tinggi. Turusy et al. (2019) pemberian dosis pupuk bio-slurry level 5 ton/ha - 30 ton/ha memberikan hasil yang tidak berbeda terhadap pertumbuhan dan produksi rumput gajah kate. Pemberian pupuk organik bioslurry pada level 25 ton/ha memberikan hasil yang terbaik terhadap pertumbuhan dan produksi rumput gajah kate. Produksi tanaman rumput benggala (Panicum maximum $c v . J a c q$ ) sangat dipengaruhi oleh faktor tumbuh tanaman meliputi air, sinar matahari maupun unsur hara baik yang berasal dari tanah maupun dari udara $(\mathrm{C}, \mathrm{H}$, O) (Purbajanti et al., 2010). Namun hal ini berbanding terbalik dengan pernyataan Arnawa et al. (2014) bahwa penggunaan bio-slurry dengan dosis 10-30 ton/ha memberikan pengaruh yang sama terhadap

Tabel 2. Produksi Berat Segar Batang (gram/tanaman).

\begin{tabular}{ccccc}
\hline \multirow{2}{*}{ Ulangan } & \multicolumn{5}{c}{ Bio-slurry } \\
\cline { 2 - 5 } & $\begin{array}{c}\text { B0ntrol } \\
\text { kon }\end{array}$ & $\begin{array}{c}\text { B1 } \\
(25 \text { gram })\end{array}$ & $\begin{array}{c}\text { B2 } \\
(50 \text { gram })\end{array}$ & $\begin{array}{c}\text { B3 } \\
(75 \text { gram })\end{array}$ \\
\hline 1 & 19,13 & 30,25 & 35,50 & 41,25 \\
2 & 20,50 & 32,00 & 35,50 & 42,50 \\
3 & 22,00 & 32,75 & 40,75 & 46,00 \\
4 & 22,25 & 37,00 & 42,75 & 46,50 \\
\hline Rataan & $20,97 \pm 1,45^{\mathrm{c}}$ & $33,00 \pm 2,87^{\mathrm{b}}$ & $38,63 \pm 3,70^{\mathrm{ab}}$ & $44,06 \pm 2,59^{\mathrm{a}}$ \\
\hline Keterangan : Rataan pada kolom yang sama dengan superskrip yang berbeda dalam huruf besar berartiberbeda \\
& sangat nyata $(\mathrm{P}<0,01)$. Rataan pada kolom yang sama dengan superskrip ns berarti berbeda tidak \\
& nyata $(\mathrm{P}>0,05)$.
\end{tabular}


produksi rumput benggala (Panicum maximum $c v$. Trichoglume). Pemberian pupuk organik merangsang pertumbuhan mikroorganisme tanah yang berperan membantu mengikat unsur hara baik dari tanah maupun udara dan membantu menggemburkan tanah (Sutedjo dan Kartasapoetra, 2005).

\section{Produksi Berat Kering Daun.}

Pengaruh perlakuan level pupuk bio-slurry terhadap produksi berat kering daun rumput benggala (Panicum maximum cv. Jacq) dapat dilihat pada Tabel 3. Produksi berat kering daun rata-rata berkisar 1,32 sampai 2,56 gram/tanaman. Hasil penelitian ini lebih tinggi di banding dengan penelitian Prado et al. (2016) yang menyatakan berat kering daun 2,7 gram. Dari perbandingan di atas menunjukan penelitian ini memiliki hasil penelitian yang lebih baik.
Hasil analisis keragaman menunjukkan bahwa perlakuan pemberian level pupuk bio-slury memberikan pengaruh yang berbeda sangat nyata $(\mathrm{P}<0,01)$ terhadap produksi berat kering daun. Uji BNJ menunjukkan level pupuk bio-slurry 30 ton/ha memberikan produksi berat kering daun tanaman yang sangat nyata $(\mathrm{P}<0,01)$. Pemberian pupuk bioslurry dengan level pupuk 30 ton/ha (B3) memberikan hasil produksi berat kering daun yang lebih tinggi. Alfred et al. (2017) Pemberian pupuk bio-slurry pada tanaman pakchoy pada dosis 20 ton/ha (2000 $\left.\mathrm{g} / \mathrm{m}^{2}\right)$ berpengaruh nyata terhadap jumlah daun, tinggi tanaman, berat segar tanaman, berat segar tanaman layak konsumsi dan berat kering. Produksi tanaman rumput benggala sangat dipengaruhi oleh faktor tumbuh tanaman meliputi air, sinar matahari maupun unsur hara baik yang berasal dari tanah maupun dari udara $(\mathrm{C}, \mathrm{H}, \mathrm{O})$

Tabel 3. Produksi Berat Kering Daun (gram/tanaman).

\begin{tabular}{ccccc}
\hline \multirow{2}{*}{ Ulangan } & \multicolumn{4}{c}{ Bio-slurry } \\
\cline { 2 - 5 } & $\begin{array}{c}\text { B0 } \\
\text { Control }\end{array}$ & $\begin{array}{c}\text { B1 } \\
(25 \text { gram })\end{array}$ & $\begin{array}{c}\text { B2 } \\
(50 \text { gram })\end{array}$ & $\begin{array}{c}\text { B3 } \\
(75 \text { gram })\end{array}$ \\
\hline 1 & 0,75 & 1,00 & 1,50 & 2,50 \\
2 & 1,50 & 1,25 & 1,75 & 2,50 \\
3 & 1,50 & 1,75 & 1,75 & 2,50 \\
4 & 1,50 & 1,50 & 2,25 & 2,75 \\
\hline Rataan & $1,31 \pm 0,38^{\mathrm{a}}$ & $1,38 \pm 0,32^{\mathrm{b}}$ & $1,81 \pm 0,31^{\mathrm{b}}$ & $2,56 \pm 0,13^{\mathrm{b}}$ \\
\hline Keterangan : Rataan pada kolom yang sama dengan superskrip yang berbeda dalam huruf besar berarti berbeda \\
\\
& sangat nyata $(\mathrm{P}<0,01)$. Rataan pada kolom yang sama dengan superskrip ns berarti berbeda tidak \\
& nyata $(\mathrm{P}>0,05)$.
\end{tabular}


(Purbajanti et al., 2010). Namun hal ini berbanding terbalik dengan pernyataan Arnawa et al. (2014) bahwa penggunaan bio-slurry dengan dosis 10-30 ton/ha memberikan pengaruh yang sama terhadap produksi rumput benggala (Panicum maximum cv. Trichoglume). Pemberian pupuk organik merangsang pertumbuhan mikroorganisme tanah yang berperan membantu mengikat unsur hara baik dari tanah maupun udara dan membantu menggemburkan tanah (Sutedjo dan Kartasapoetra, 2005).

\section{Produksi Berat kering Batang.}

Pengaruh perlakuan level pupuk bio-slurry terhadap produksi berat kering batang rumput benggala (Panicum maximum $(v . J a c q$ ) dapat dilihat pada Tabel 4. Produksi berat kering batang berkisar 3,13 sampai 6,19 gram/tanaman. Hasil penelitian ini lebih tinggi dari penelitian Widana et al. (2005) 5,59 gram. Dari perbandingan di atas menunjukan penelitian ini memiliki hasil penelitian yang lebih baik.

Hasil analisis keragaman menunjukkan bahwa perlakuan pemberian level pupuk bio-slurry memberikan pengaruh yang berbeda sangat nyata $(\mathrm{P}<0,01)$ terhadap produksi berat kering batang. Uji BNJ menunjukkan level pupuk bio-slury 30 ton/ha memberikan produksi berat kering batang yang sangat nyata $(\mathrm{P}<0,01)$

Pemberian pupuk bio-slurry dengan level pupuk 30 ton/ha (B3) memberikan hasil produksi berat kering batang yang lebih tinggi. Susanti et al. (2016) menyatakan bahwa pemberian pupuk bioslurry level 5 ton/ha, 10 ton/ha, 15 ton/ha tidak berpengaruh terhadap produksi, namun pemberian perlakuan 5 ton/ha memberikan hasil terbaik terhadap produksi Stylosanthes guianensis dibandingkan dengan perlakuan lainnya.

Tabel 4. Produksi Berat Kering Batang (gram/tanaman)

\begin{tabular}{|c|c|c|c|c|}
\hline \multirow[b]{2}{*}{ Ulangan } & \multicolumn{4}{|c|}{ Bio-slurry } \\
\hline & $\begin{array}{c}\text { B0 } \\
\text { kontrol }\end{array}$ & $\begin{array}{c}\text { B1 } \\
(25 \text { gram })\end{array}$ & $\begin{array}{c}\text { B2 } \\
(50 \text { gram })\end{array}$ & $\begin{array}{c}\text { B3 } \\
\text { (75 gram) }\end{array}$ \\
\hline 1 & 2,50 & 3,75 & 6,00 & 5,25 \\
\hline 2 & 2,75 & 4,50 & 5,25 & 6,00 \\
\hline 3 & 3,50 & 4,75 & 5,50 & 6,25 \\
\hline 4 & 3,75 & 4,75 & 6,25 & 7,25 \\
\hline Rataan & $3,13 \pm 0,60^{\mathrm{c}}$ & $4,44 \pm 0,47^{b}$ & $5,75 \pm 0,47^{\mathrm{a}}$ & $6,19 \pm 0,83^{\mathrm{a}}$ \\
\hline
\end{tabular}


Produksi tanaman rumput benggala sangat dipengaruhi oleh faktor tumbuh tanaman meliputi air, sinar matahari maupun unsur hara baik yang berasal dari tanah maupun dari udara $(\mathrm{C}, \mathrm{H}, \mathrm{O})$ (Purbajanti et al., 2010). Namun hal ini berbanding terbalik dengan pernyataan Arnawa et al. (2014) bahwa penggunaan bio-slurry dengan dosis 10-30 ton/ha memberikan pengaruh yang sama terhadap produksirumput benggala (Panicum maximum $c v$. Trichoglume).Pemberian pupuk organik merangsang pertumbuhan mikroorganisme tanah yang berperan membantu mengikat unsur hara baik dari tanah maupun udara dan membantu menggemburkan tanah (Sutedjo dan Kartasapoetra, 2005).

\section{KESIMPULAN}

Pemberian pupuk bio-slurry dengan level pemupukan 30 ton/ha menghasilkan produksi rumput benggala (Panicum maximum $c v$. Jacq) yang paling tinggi dilihat dari ukuran berat segar dan berat kering pada daun dan batang.

\section{DAFTAR PUSTAKA}

Agus, S. 2013. Pengolaan dan Pemanfaatan Bio-Slurry. Https:// Www. Academia. Edu/10389621/ Pengolaan dan Pemanfaatan BioSlurry.
Alfred, K.M., A. Sutikno, S. Yosefa. 2017. Pemberian pupuk organik Bio-Slurry padat tanaman Pakchoy (Brassica Chinensis L). JOM Faperta Universitas Riau 4(2): 1-11

Arnawa, I. W., I.K.M. Budiasa, N.M. Witariadi. 2014. Pertumbuhan dan produksi rumput benggala (Panicum maximum $c v$. Trichoglume) yang diberi pupuk organik dengan dosis berbeda. J. Peternakan Tropika 2(2): 225-239

Fanindi, A. dan E. Sutedi. 2014. Karakter morfologi rumput benggala (Panicum maximum cv. Gatton) yang ditanam menggunakan jenis benih berbeda. JITV. 19(1): 1-8.

Fernandes, D. F., K.B.R. Allan, J. Liana, A.C. Marcel, B.M.J. Geraldo, J.B. Gustavo. 2014. Forage yield and nutritive value of Panicum maximum Genotypes inthe Brazilian Savannah. Brasil. Journal. Sci. Agric. 71(1): 2329

Prado, C, H, B, D, A. Lívia, H, G De C-B. Érique, C. Carlos A, M. 2016. Leaf dynamics of Panicum maximum under future climatic changes. PLOSONE|DOI:10.1371/journal.pon e. 0149620

Purbajanti, E.D., D. Soetrisno., E. Hanudin dan S.P.S. Budi. 2010. Penampilan fisiologi dan Hasil Rumput Benggala (Panicum maximum cv. Jacq) pada Tanah Salin Akibat Pemberian Pupuk Kandang, Gypsum dan Sumber Nitrogen. J. Agron. Indonesia 38(1):75-80.

Susanti, N. P. R. N., A.A.A.S. Trisnadewi, dan W. Witariadi. 2016. Pertumbuhan dan produksi hijauan Stylosanthes Guianensis pada berbagai level aplikasi pupuk Bio- 
Slurry. J. Peternakan Tropika 4(1): $268-284$.

Sutedjo, dan A.G. Kartasapoetra 2005.

Pengantar Ilmu Tanah. Penerbit Rineka Cipta. Jakarta.

Turusy, R. D. P., I. K. M. Budiasa, dan I. G. Suranjaya. 2019. Pertumbuhan dan produksi rumput gajah Kate (Pennisetum Purpureum cv. Mott) pada berbagai level pupuk slurry dan bio slurry sapi. J. Peternakan Tropika 7(1): $51-65$.

Widana, G. A. A, N. G. K. Roni, dan A. A. S. Trisnadewi 2005. Pertumbuhan dan produksi rumput benggala (Panicum maximum cv. Trichoglume) pada berbagai jenis dan dosis pupuk organik. J. Peternakan Tropika 3(2): $405-417$.

Witariadi, N.M. dan N. Candraasih, 2018. Produktivitas rumput Panicum maximum yang dipupuk dengan jenis dan dosis Bio-Slurry berbeda. Jurnal Pastura Tumbuhan Pakan Tropik 7(2): 57-114. 